\title{
A EVOLUÇÃO DO PENSAMENTO GEOGRÁFICO E O CONCEITO DE REGIÃO COMO CATEGORIA DE ANÁLISE
}

Jânio Gomes do Carmo ${ }^{1}$, Rafael Gotardi Brússolo ${ }^{2}$

'Universidade Estadual Paulista - FCT-UNESP, Mestrado em Geografia, Presidente Prudente, SP. ${ }^{2}$ Universidade de São Paulo - USP, Escola de Engenharia de São Carlos, Ciência da Engenharia Ambiental, São Carlos, SP. E-mail: rgbrussolo@usp.br

\section{RESUMO}

O objetivo central deste texto consiste na realização de um exercício teórico a respeito do conceito de região. Nesse processo é de suma importância caracterizar teoricamente o reconhecimento da Geografia como ciência. Na construção desse exercício passamos pelas várias correntes filosóficas da Geografia, entre elas se destacam a Geografia Clássica, a Nova Geografia, a Geografia Crítica, entre outras mais. Sabe-se que, a própria Geografia no decorrer de sua confirmação como ciência geográfica, sofreu abalos e rupturas paradigmáticas em seu conteúdo e, ainda hoje sofre constantes reformulações. Nessa perspectiva, o conceito de região não foge a regra, pois seu processo não poderia ser diferente, em detrimento de o conceito encontrar-se inserido numa das áreas científicas da Geografia. Recentemente, a região e a Geografia passam por mudanças conceituais e metodológicas influenciadas pela constante renovação do pensamento científico, influenciados pelo processo de Globalização.

Palavras-chave: Região. Geografia. Correntes Geográficas. Globalização.

\section{THE EVOLUTION OF GEOGRAPHICAL THOUGHT AND THE REGION AS CONCEPT ANALYSIS CATEGORY}

\begin{abstract}
The main objective of this text is in carrying out an exercise on the concept of region. This process is very important theoretically characterize the recognition of geography as a science. In the construction of this exercise we go through the various philosophical currents of Geography, among them stand out the Classical Geography, New Geography, Critical Geography, among other more. It is known that the very Geography during their confirmation as geographical science, suffered concussions and paradigmatic ruptures in their content and, still suffers constant reformulation. In this perspective, the concept of region is no exception to rule because their process could not be otherwise, to the detriment of the concept lie inserted in one of the scientific fields of geography. Recently, the region and the Geography go through conceptual and methodological changes influenced by the constant renewal of scientific thought, influenced by the globalization process.
\end{abstract}

Keywords: Region. Geography. Geographic Currents. Globalization.

\section{INTRODUÇÃO}

O campo de estudos da Geografia foi construído por meio de teorias e filosofias que procuravam através do método científico desenvolver o conhecimento geográfico. Sabe-se que todo conhecimento, dentro de qualquer área científica é composto por conceitos e temas consolidados por meio de teorias e métodos, cujos objetivos centrais seriam afirmar ou refutar ideias; no caso estudado estabelecer a Geografia como ciência.
A importância da Geografia como ciência tem seu início no XIX, através das discussões elaboradas por várias correntes geográficas, por exemplo, o positivismo e o determinismo, cujos estudos evidenciaram no reconhecimento da Geografia, que diante das análises científicas procurou-se firmar como disciplina. Para o seu reconhecimento, os conceitos foram elaborados e reelaborados, os temas foram debatidos e discutidos entre os pesquisadores da época, que afirmaram, refutaram e reformularam novos 
conceitos por meio do conhecimento adquirido, por meio de investigações empíricas.

Entretanto, num primeiro momento, a utilização do método geográfico torna-se irrefutável para a descoberta da categoria geográfica, sendo esse o ponto de discussão entre os estudiosos da época, cujos pensamentos sobre os estudos geográficos se divergiam. A afirmação desse processo veio com a consolidação da Geografia como disciplina. Consequentemente, as preocupações se concentraram em conceituar as categorias geográficas, dentre elas, a elaboração do conceito de região.

Assim, coube na análise dos diferentes tipos de métodos a afirmação dos conceitos geográficos. Nesse trabalho, buscou-se compreender a importância da metodologia científica para o surgimento da disciplina de Geografia. Amparou-se no estudo do conceito de região como forma de entendimento.

O método é considerado um instrumento em que são realizadas as análises interpretativas das realidades objetivas exercida por um investigador. Nesse processo são levantadas as verdades científicas, orientadas e refletidas por meio de estudos realizados pelo investigador.

Três são os principais métodos científicos a serem compreendidos, dentre eles temos: o método hipotético-dedutivo (OBJETO prevalece diante do sujeito); o método fenomenológico hermenêutico (SUJEITO realiza a descrição do objeto não tomando essência das coisas); o método dialético (a relação entre o sujeito e o objeto ocorrerá de forma contraditória).

Nesse texto não vamos especificar cada método, pois a compreensão de cada um deles seria algo complexo e desnecessário na presente reflexão. Em análises mais profundas sobre a metodologia em Geografia, a obra "Geografia e Filosofia: contribuição para ensino do pensamento geográfico" de autoria Eliseu Savério Sposito é umas das grandes referências.

Focar-se-á esta análise no estudo do conceito de região, pois acredita-se para sua formulação, reconhecimento e afirmação ao longo dos anos, o entendimento dos métodos científicos foi de suma importância para o desenvolvimento da disciplina de Geografia.

O estudo da região e das suas aplicações nas pesquisas geográficas por longos anos foram as pautas das discussões a respeito da sua elaboração como conceito. Estudo este que entrelaçou no âmago da ciência desde a sua origem, que atualmente realça uma série de discussões de cunho conceitual, teórico e metodológico, como esse exercício reflexivo a respeito da região.

Cabe salientar que, discutir a respeito do conceito região não é um trabalho fácil, que requer um conhecimento amplo, haja vista os inúmeros fatores inseridos no campo conceitual e empírico, sobretudo o grande número de autores que o discute. Atualmente, a destreza torna-se um desafio ainda maior por conta do processo de articulação da região/regionalização, que se encontra inserido no desenvolvimento territorial, instituídos principalmente com a Globalização.

Para tanto, este trabalho é um exercício teórico e tem como base a obra Região $e$ Geografia da autora Sandra Lencioni, que por meio do diálogo com outros atores buscou compreender como se deu o desenvolvimento teórico e metodológico na Geografia, principalmente no que concerne ao conceito de região no contexto da evolução do pensamento geográfico e sua aplicabilidade nos dias atuais. Para tanto, autores como Milton Santos, Ruy Moreira, Roberto Lobato Côrrea, entre outros, foram consultados procurando 0 melhor entendimento do conceito de região.

\section{A Influência das Escolas Francesa e Alemã na Evolução do Conhecimento Geográfico e na Elaboração do Conceito de Região}

A evolução do pensamento geográfico consiste nos relatos deixados pelos filósofos gregos $^{1}$, tais como: Tales de Mileto através do conhecimento matemático e astronômico, Pitágoras com os elementos da natureza, "terra, água" e Aristóteles com a esfericidade da Terra e a ideia de anecúmeno e ecúmeno, durante a Antiguidade Clássica. Esses filósofos realizaram seus estudos com base na descrição e comparação dos lugares visitados, fatores estes importantes para a elaboração do saber geográfico.

O conhecimento difundido pelos povos gregos levou ao avanço no campo científico, dentre eles: a explicação do universo, das influências climáticas, das marés, dos rios da superfície da Terra, conforme nos atenta Lencioni (1999).

Para a mesma autora, os gregos foram os primeiros a desenvolver estudos voltados para a regionalização. Hecateu de Mileto elaborou o

1 - Foram os pioneiros na construção do método, por meio da explicação dos fenômenos da natureza (LENCIONI, 1999, p. 36). 
primeiro mapa-múndi, posteriormente, Pitágoras dividiu a terra em zonas climáticas.

Com a conquista dos povos gregos pelos romanos, grande parte do conhecimento científico foi submetido às atividades expansionistas, porém os legados deixados pelos gregos não foram extintos, haja vista que, os romanos necessitavam "[...] nutrir-se do saber pelos gregos, produzido" (MOREIRA, 1994, p. 17). Durante a dinastia romana, os viajantes contribuíram para o estudo da região, principalmente com os avanços da navegação. A região passa a ser entendida como um espaço ocupado, que apresenta características físicas e biológicas (fauna e flora) próprias de determinados lugares, confirmados por meio dos atributos físicos, naturais dos lugares visitados, elencados nas grafias dos viajantes. Entendia-se a região nesse período como um estudo corográfico realizada pelos gregos no estudo da superfície da terra, de acordo com Moreira (1994).

No entanto, fazer Geografia nesse período era descrever e comparar os elementos da natureza, analisando as características físicas e biológicas por meio da interpretação da paisagem. Ao tratar do conhecimento geográfico, os estudos foram conduzidos para a "separação da Geografia como ciências da natureza ou como ciências do homem" (LENCIONI, 1999 p. 188).

A Idade Moderna trouxe novos rearranjos no estudo da evolução do pensamento científico, consequentemente, para o entendimento da região como conceito geográfico. Contudo, a Geografia ainda precisava se concretizar como disciplina. Nesse processo, os estudos geográficos realizados pelas escolas francesa e alemã foram de suma importância para o desenvolvimento do conhecimento geográfico e da consolidação da Geografia como disciplina.

As correntes teórico-metodológicas (positivismo "escola francesa" e determinismo "escola alemã") influenciaram na passagem da Antiguidade Clássica para o pensamento científico moderno. Essa nova perspectiva estabelece um novo modo de analisar a natureza e a sociedade, elencando elementos fundamentais para 0 desenvolvimento da geografia. Assim, “[...] o debate entre o determinismo e o possibilismo e entre o positivismo e historicismo promoveram a multiplicação dos estudos, geográficos e fizeram avançar, teórica e metodologicamente, a disciplina Geografia". (LENCIONI, 1999, p. 99).

A escola alemã foi a principal difusora do conhecimento geográfico, sobretudo a partir do sec. XIX com Kant (natureza dotada de vida e movimento), Humboldt e Ritter (contribuíram para o desenvolvimento da geografia científica e para a difusão nas universidades) e Ratzel, cujas acepções foram proferidas com base na teoria do determinismo geográfico e de espaço vital.

Os estudos desenvolvidos por Humboldt e Ritter alcançaram patamares importantes, principalmente no cerne da difusão do conhecimento geográfico nas universidades e nas escolas. Os estudos desenvolvidos por Humboldt tiveram como base a geografia ecológica. Por outro lado, Ritter procurou fazer com que a Geografia acadêmica e escolar ganhasse forma e fosse ministrada como disciplina nas universidades e não mais como disciplina extracurricular de História. Acreditava que "[...] o antropocentrismo, uma unidade cujo ponto de partida e finalidade de servir ao homem". (MOREIRA, 1994, p. 26). Nessa perspectiva, os estudos da Geografia são analisados em sua totalidade, por meio da relação entre a natureza e o homem, através da ação dos fatos naturais e humanos, onde os homens vivem e sobrevivem.

Lencioni (1999) afirma em sua obra que Ratzel buscou nos manuscritos de Darwin elementos para compreender a realidade, fazendo uso da teoria evolucionista. Parte do pressuposto de que o homem é determinado pelo meio natural e "[...] as condições naturais condicionam a forma de vida [...] e que os agrupamentos humanos buscam ampliar seu espaço de vida mesmo em detrimento dos seus vizinhos" (LENCIONI, 1999, p. 82).

Dessa forma, Moreira (1994) ao fazer uma leitura sobre os estudos de Ratzel ressalta que, o mesmo proferiu em seus estudos a luta das espécies pelo domínio do espaço e a presença da sociedade organizada pelo poder do Estado desencadearia no pensamento linear "[...] os homens agrupam-se em Sociedade, e a Sociedade é o Estado, o Estado é um organismo. A Sociedade e o Estado são fruto orgânico do determinismo do meio" (MOREIRA, 1994, p. 33).

Para a expansão do conhecimento geográfico era preciso que a geografia encontrasse um método de análise para se tornar uma ciência. A escola alemã passou a defender que o verdadeiro método é aquele que segue os passos da natureza. Acreditava que para a Geografia adquirir o status de ciências "[...] era preciso ordenar o material reunido nas observações, buscando conexões causais; levando a investigação geográfica a um grau superior de 
especulação e a classificaria como ciência" (CAMPOS, 2001, p. 25).

Nesse período a Geografia ainda não tinha seu objeto de estudo definido. As referências conceituais estavam inseridas nas ciências naturais, considerado um conhecimento descritivo, que observava os elementos natureza, conforme Moreira (1994).

Nesse processo é importante ressaltar os fatores externos presentes na Europa. A disputa territorial entre Alemanha e França influenciou nas proposições sobre a evolução do pensamento geográfico evidenciado na formação das correntes metodológicas, refutadas por meio da distinção das escolas geográficas.

O desenvolvimento do conhecimento científico na Alemanha ocorreu durante um período de reivindicações e lutas pela disputa territorial com a vizinha França, culminando com a eclosão da I Guerra Mundial. Em meio às disputas territoriais surge a escola francesa de Geografia. Trata-se de estudos voltados para a informação através da descrição, ensinada nas universidades como disciplina auxiliar de História. É nesse contexto que a Geografia irá se firmar como disciplina.

Por outro lado, os estudos desenvolvidos no campo geográfico na Alemanha eram direcionados para territorializar as suas fronteiras. Os estudos eram baseados na Geografia Clássica.

\begin{abstract}
A Geografia na Alemanha passa por transformações profundas sem romper com o seu caráter já institucionalizado. [...] muda para melhor servir, agora, a um senhor ainda mais poderoso que os que anteriormente serviram: o Capital (MOREIRA, 1994, p. 29).
\end{abstract}

Na França, o contexto histórico foi muito importante para compreender a formação da escola francesa de Geografia, pois nesse país a revolução burguesa foi um fator de destaque para a eclosão do pensamento geográfico francês. As disputas territoriais com a vizinha Alemanha influenciaram nas discussões política e ideológica da época. Dessa forma, surge o pensamento geográfico na França como forma de combater o pensamento de Ratzel na Alemanha.

A Geografia desenvolvida na França encontrava-se atrasada do ponto de vista teórico, pois era uma Geografia [...] informativa e descritiva, ensinada nas universidades como disciplina complementar do ensino de história (MOREIRA, 1994, p. 34). Nos trabalhos de Ratzel eram constantes as críticas desenvolvidas e fundamentadas no desenvolvimento da Geografia francesa por apresentar características da Antiguidade Clássica.

O pensamento francês foi delineado pelos estudos desenvolvidos por Paul Vidal de La Blanche, estudioso da corrente teórica possibilista. A escola francesa de Geografia apoiou-se no funcionalismo positivista da época, permanecendo até meados da metade do século XX (MOREIRA, 1994).

Os estudos desenvolvidos por Vidal de La Blache restabeleceram a referência para a compreensão e a análise do estudo direcionado para a região. Tornou-se fundamental para o desenvolvimento de esboços teóricos da Geografia em várias áreas do planeta. A importância desta análise consistiu na especialização do estudo geográfico da região, contribuindo para o surgimento de novas áreas na Geografia, por exemplo, a Geografia Agrária.

Os trabalhos desenvolvidos na França eram descritivos e direcionados para o estudo da região como categoria de análise, destacando às características físicas e naturais únicas, sendo que, seus resultados, passaram a ser apresentados em forma de monografias.

[...] As monografias
regionais acabaram
construído uma Geografia
que destacava o caráter
único de cada estudo
regional, sem preocupação
com o estabelecimento de
leis e princípios gerais no
conhecimento da
realidade. Portanto acabou
comprometendo o status
científico da disciplina e
conduzindo a um novo
impasse teórico: a
dicotomia entre a
Geografia regional e
Geografia geral (LENCIONI,
1999, p. 189).

Nesse trabalho não vamos nos ater a análise aprofundada da evolução do pensamento geográfico, cujo historiógrafo Nelson Werneck Sodré o descreveu veemente em sua obra "Introdução a Geografia: geografia e ideologia"; Antonio Carlos Robert Moraes em sua obra 
"Geografia pequena história crítica", além do geógrafo Ruy Moreira com a obra "O que é a Geografia". O objetivo desse texto é elencar algumas das principais contribuições deixadas pelos autores acima citados, e por outros autores que abordaram a discussão em torno à elaboração do conhecimento geográfico e do conceito de região, em específico o geógrafo Ruy Moreira.

Sendo assim, os estudos realizados por Humboldt e Ritter, buscou, através de diferentes caminhos, compreender o estudo geográfico, o primeiro com sua concepção naturalística e o segundo com uma visão antropocêntrica, concebiam a Terra com um todo harmônico com múltiplas relações. O pensamento de Humboldt influenciou na análise da Geografia geral. Já Ritter desencadeou seus estudos em ações comparativas, concentrando mais no particular do que no geral, contribuindo para o desenvolvimento do estudo regional.

Kant foi um idealizador do conceito de região, pois ele afirmava que o espaço geográfico estava inserido na região. Para (LENCIONI, 1999, p. 79), Kant ao trabalhar com a concepção de espaço geográfico difere-se do "espaço matemático", e ainda afirma que o mesmo "encontra-se dividido em regiões que se constituem no substrato da história dos homens". O pensamento kantiano mostra a clareza das ideias ao trabalhar com o estudo geográfico, dividindo sua análise no particular e no geral, formulando novas diretrizes para o crescimento da ciência geográfica.

Mas foi na escola francesa que se desenvolveu o estudo regional, com base no pensamento de Paul Vidal de La Blache "Possibilista". Este autor fazia uso do método indutivo, e por conta disso, suas ações sofreram com os ataques teóricos e metodológicos da corrente alemã de caráter "determinista", cujo principal difusor era Ratzel.

Desse modo, a Geografia produzida no fim do sec. XIX e início do sec. XX vivenciava a disputa entre as correntes teórico-metodológicas, a determinista vs a possibilista não valorizado o método regional, conforme salienta Corrêa (2007), Lencioni (1999) e Moreira (1994).

É em meio as constantes disputas teórica e metodológica que surge o conceito de região.

\section{A Região como Categoria Geográfica}

A análise do conceito de região teve mais ênfase na França, principalmente no século XIX, durante o período de grandes disputas territoriais com a vizinha Alemanha (Alsácia e Lorena) - cujos fatos acabaram por culminar na I Guerra Mundial. A abordagem francesa se deu sob os estudos de Paul Vidal de La Blanche. Este autor considerava que o termo "região" seria uma unidade de análise geográfica que demonstrava a própria forma dos homens em se organizarem no espaço, conforme os estudos de Moreira (1994) e Lencioni (1999).

A Geografia francesa ainda carregava os traços tradicionais da Antiguidade Clássica, pautados na análise descritiva do objeto de estudo, que de certa forma contribuiu para avançar teórica e metodologicamente nas discussões em torno do campo da Geografia regional. Cabe ressaltar a importância da elaboração das "monografias regionais", que visavam buscar o conhecimento dos elementos, diante dos fenômenos diagnosticados através da observação e descrição do lugar estudado.

O precursor do estudo regional na França foi Vidal de La Blache, com sua perspectiva possibilista, onde o homem e a natureza se encontram em harmonia. Santos (1988, p. 52) afirma que "a Geografia é uma ciência dos lugares" e é através da descrição das regiões que se compreenderá a história dos lugares [...]". A perspectiva lablachiana procurou compreender a relação entre o homem e a natureza por meio da "[...] análise detalhada do meio físico, das formas de ocupação das atividades humanas e de como o homem se ajusta na natureza" (LENCIONI, 1999, p. 105). Para La Blache, a região encontra-se evidenciada na paisagem.

Nessa perspectiva, os resultados das análises desenvolvidas na abordagem de campo deveriam ser apresentados por meio da elaboração de monografias. De certa forma, era importante abarcar as relações causais entre os fenômenos para observar e compreender os lugares. Portanto, La Blache não se preocupava em formular leis e nem aplicar suas análises, mas sim compreender as relações entre o homem e o meio, através das evidencias naturais observadas pela descrição da paisagem.

Para Corrêa (2007), a divisão regional desenvolvida por La Blache apresentava características do clima, da vegetação e do tipo de solo, elementos estes, importantes do ponto fronteirístico da região. "[...] o importante é que na região haja uma combinação específica da diversidade, uma paisagem que acabe conferindo singularidade aquela região" (CORRÊA, 2007, p. 29).

Entre o início do século $X X$ até meados dos anos de 1960, prevaleceu os estudos 
desenvolvidos por La Blache, com base no conceito de região natural e região geográfica. Nesse estudo, este autor procurou fazer uma relação entre o Homem e a Natureza, presentes no mesmo quadro analítico (GOMES, 2009).

O trabalho de La Blache recebeu severas críticas por não abordar as leis naturais e por destacar um caráter regional único em suas análises. Estes estudos, de certa forma viriam a contribuir para o distanciamento da ideia de Geografia como ciência. As críticas direcionadas para 0 trabalho dele foram realizadas principalmente pela Nova Geografia (Escola Anglosaxônica), cujas bases do pensamento centralizamse no neopositivismo (teorético e qualitativo) onde as discussões desencadearam-se nas normas científicas, com a finalidade de compreender os objetos descritos.

A Escola Anglo-saxônica desenvolveu estudos contrários ao funcionalismo positivista. Com a implantação dessas novas teorias, os chamados "neopositivistas" questionam a descrição exacerbada dos possibilistas. Os autores dessa corrente passaram a matematizar a paisagem, contribuindo para quantificação dos dados levantados em campo (MOREIRA, 1994).

O mesmo autor ainda ressalta que

[...] em vez da descrição da morfologia da paisagem, toma seu lugar uma rigorosa tipologia de padrões espaciais. Em vez da pesquisa de campo, toma seu lugar o computador. Em vez da descrição subjetiva, toma seu lugar a objetividade descritiva da linguagem matemática (MOREIRA, 1994, p. 46).

Hartshorne desempenhou um papel importante com o seu estudo de áreas-unidades, que define a região como uma área de construção intelectual. Ele ainda define a região como um campo representando seu caráter único (CORRÊA, 2007).

A região é um produto mental, uma forma de ver o espaço que coloca em evidência os fundamentos da organização. A região é ao mesmo tempo o campo empírico de observação e o campo da verificação das relações gerais (GOMES, 2009, p. 52).

Hartshorne ${ }^{2}$ faz uma crítica à Geografia clássica promovendo novos debates em torno da discussão a respeito do conceito de região. Para o autor, a Geografia clássica de caráter descritivo jamais poderia alcançar o estado científico, devido ao fato de ficar restrita a descrição dos objetos de estudo, não se atendo em estabelecer relações, análises e conclusões; restringia o campo do conhecimento não procurando compreender as relações inerentes, existentes no encontro das ciências da natureza com as ciências humanas.

Ao analisar a perspectiva hartshorniana, Lencioni (1999) salienta que a Geografia deveria "descrever e interpretar o caráter variável da terra, de lugar a lugar, como o mundo do homem" (LENCIONI, 2009, p. 126). A mesma autora afirma que: Hartshorne usou o conceito de diferenciação de áreas para diferenciar as distintas parcelas da superfície terrestre. Lencioni lembra que: o termo utilizado por Hartshorne (diferenciação de áreas) é visto pelo autor como uma rejeição ao termo "região", ressaltando ainda o "descompromisso ou uma ruptura, com o sentido de região e com às noções a ela agregadas" (GOMES, 1985, apud LENCIONI, 2009, p. 127).

Nesse processo é importante ressaltar o pensamento de Hartshorne a respeito das atribuições dadas por ele sobre o conceito de região. Ele atribui o papel do pesquisador na elaboração do conceito de região ou até mesmo no termo "áreas-unidades", ao afirmar em suas observações que, tanto o termo região quanto as "áreas-unidade" não são autoevidentes, ou seja, "uma construção intelectual" fruto das análises realizadas pelo pesquisador (LENCIONI, 1999).

Os estudos desenvolvidos pela perspectiva hartshorniana desencadeou as novas diretrizes para o entendimento das discussões a respeito do conceito de região. Outros autores realizaram novas considerações a fim de compreender a realidade espacial do termo região. Esse processo resultou no aparecimento de um novo aporte teórico-metodológico no campo geográfico, fundamental para o surgimento do pensamento geográfico, desencadeado pela nova Geografia,

\footnotetext{
2. Para Hartshorne, a Geografia é, ao mesmo tempo, uma ciência da natureza e da sociedade. Afirma que a Geografia deve procurar compreender como os fenômenos (todos aqueles que apresentam uma dimensão espacial) se combinam numa área da superfície terrestre (LENCIONI, 2009, p. 126).
} 
estabelecido a partir dos anos de 1960, principalmente entre os países anglo-saxões.

Com a implantação da Nova Geografia no campo geográfico, instituem-se novos rearranjos fundamentados em teorias e métodos geográficos, cujas ações pautavam-se em compreender as relações entre a natureza e o homem, através dos modelos matemáticos. Nesse contexto, a velha questão do determinismo geográfico ressurgiu de maneira diferente, reciclada. Novos elementos serão inclusos na abordagem determinista não ficando restrito, somente ao enfoque entre a relação "homem vs meio". Aplicou-se na discussão as variáveis matemáticas, além da aplicação da teoria geral do sistema.

Com a implantação da nova Geografia os questionamentos da Geografia se pautaram na discussão a respeito dos modelos matemáticos, e que os problemas encontrados nas regiões estudadas eram oriundos das imperfeições das técnicas e dos modelos de análises utilizados.

A partir da segunda metade do século XX, os questionamentos geográficos passaram a destacar os aspectos sociais, por conta do processo de urbanização, industrialização e centralização do poder. Estes estudos, de certa forma contribuíram para novos instrumentos de análise regional, elencando as características econômicas por meio dos conceitos "fixos e fluxos" de pessoas, mercadorias e capital.

Nessa nova perspectiva são avaliadas as regiões, cujos parâmetros avaliativos encontramse descritos através das análises estatísticas de modo invariável, apresentando características homogêneas. Por sua vez, o processo de circulação entre os elementos inseridos no território e suas respectivas interações, de modo a possibilitar maior fluidez na circulação, estando a serviço do Capital, considera essa abordagem como funcional. Esses serão os novos elementos apresentados pela Geografia Teorética, cujas ações/intervenções encontram-se pautadas nas variáveis matemáticas.

As regiões funcionais são definidas de acordo com o movimento de pessoas, mercadorias, informações, decisões e ideias sobre a superfície da Terra. Identificam-se, assim, regiões de tráfico rodoviário, fluxos telefônicos ou matériasprimas industriais, migrações diárias para o trabalho, influência comercial das cidades, etc. Já as regiões homogêneas referem aos fenômenos que se comportam, cada um deles, com especificidade própria (CORRÊA, 2007, p. 35).

Ao se referir a vertente teorética, a concepção de região está entrelaçada com o espaço regional, através do planejamento das ações. Ao trabalhar com os métodos estatísticos, matematizando o espaço diagnosticado, por meio de intentar melhorias no sistema de circulação, torna-se mais fácil compreender o processo de divisão regional.

Sendo assim, Corrêa (2007, p. 49), entende que "[...] a região sob a intervenção planejadora passa a ficar sob maior controle do capital e de seus proprietários [...]", o que, via de regra, pode resultar na configuração regional excludente, por um lado e, por outro, provedora de privilégios e da manutenção do poder.

Assim, com a difusão da Globalização, cujas ações, processos e formas acontecem de forma intensa e veloz, o estudo do conceito de região torna-se fundamental no entendimento das ações globalizadoras que se espalham em diferentes pontos do espaço.

\section{As Novas Perspectivas do Estudo Regional}

O processo de globalização promoveu mudanças em todo o mundo, de modo intenso e veloz, não atendendo mais as particularidades locais. Outrora as ações concentravam-se em análises particulares contribuindo para a divisão do espaço em várias regiões que, eram autossuficientes, quase não mantendo relações entre si.

Nessa concepção, a globalização exerceu um papel importante, com o advento da II Revolução Industrial, principalmente ao sobrepor os avanços tecno-científicos em detrimento de novos espaços que se transformavam, em detrimento das ações articuladas no território, instaurando novas formas e funções para os agentes sociais nele inserido.

O conceito de região passa a ter novas implicações levando em consideração o processo de organização e reorganização territorial. Elencam-se novas diretrizes desse processo, dentre elas, as inferências no campo político e o papel exercido pelo Estado no desenvolvimento 
econômico e social de uma determinada região, e também, no direcionamento de políticas públicas para os distintos grupos de seguimentos sociais.

Nessa concepção, evidencia-se mais uma vez, o caráter dinâmico e multifacetado do tecido regional, ocasionado pela multiplicidade de agentes e interesses que convergem no sentido de garantir-lhe determinadas formas e funções. Nessa acepção, tantas serão as possibilidades de recortes regionais quantas forem às ideologias de Estado, a política subjacente ao processo de construção e do desenvolvimento da região.

Por outro lado, as ações endógenas (desenvolvimento, infraestrutura e bens materiais/imateriais) ocorridas dentro da região alcançaram patamares inesperados (rompendo fronteiras), principalmente com o avanço econômico e tecnológico. A capitalização do território favoreceu o desenvolvimento exógeno em algumas regiões. Nessa perspectiva, as sociedades mais evoluídas passaram a operar as transformações sobre os espaços por elas dominados, favorecendo as guerras fiscais entre determinados territórios, bem como a descentralização industrial, isto é, tais medidas, acarretaram na exclusão regional e no desenvolvimento desigual no Brasil, bem como em outros países.

Referindo sobre o processo de capitalização da economia, o agente social "homem" é marcado por uma "crescente internacionalização da economia capitalista com uma total interdependência das diferentes economias nacionais e uma nova divisão internacional do trabalho" (CASTELLS, 1986 apud SANTOS, 1988, p. 46). No que se refere à espacialização do capital e a produção mundial, sabe-se que ela se espalha em todos os cantos do planeta e se especializa regionalmente, conforme (Santos, 1988).

Em detrimento dessas ações, temos que o desenvolvimento destas relações acentuou no âmbito global e principalmente no regional, um desenvolvimento desigual nas formas de uso e apropriação dos recursos, que de certa forma culminou com os privilégios, o poderio dentro das regiões e a sua sobreposição sobre as outras, reiterando a diferenciação de áreas.

As sociedades [...] tiveram, ao longo do tempo e do espaço, um desenvolvimento diferenciado, isto é, os processos internos de diferenciação e a difusão dos processos de mudança deram-se de modo desigual. Assim, o aparecimento da divisão social do trabalho, da propriedade da terra, dos meios, das técnicas de produção, das classes sociais e suas lutas, tudo isso se deu com enorme distância em termos espaço-temporais, levando a uma diferenciação intra e intergrupos. Do mesmo modo, a difusão dos processos de mudança fezse desigualmente, reforçando a diferenciação de áreas (CORRÊA, 2007, p. 43).

Em se tratando da diferenciação de áreas, tal como elencado, considera-se como o ponto nodal para o desenvolvimento e compreensão do estudo da região. Analisando as novas acepções do estudo sobre região temos que: "as crescentes relações com áreas cada vez mais distantes, suprimem as veleidades de autonomia [...] aparecem como as distintas versões da mundialização" (SANTOS, 1988, p. 46).

$\mathrm{Na}$ atualidade, o edifício regional é rapidamente construído e reconstruído, devido à aceleração dos processos globais que territorializareterritorializa-desterritorializa novas ações junto aos seus atores sociais, que em sua grande maioria são heterogêneos. Nesse processo, há de ser considerado o fato de que, mesmo havendo este "desmoronamento" do que se entendia como região, ela não deixa de existir, e cada vez mais se torna importante compreender 0 seu funcionamento elencado os fatores endógenos e exógenos atrelados ao desenvolvimento econômico mundial e seu rebatimento no território.

Nesse trabalho não vamos nos ater a análise do conceito de território, cujo geógrafo Marco Aurélio Saquet tem contribuindo com novas abordagens em sua obra "Abordagens $e$ concepções sobre o território" "Territórios $e$ territorialidades: teoria, processos e conflitos"; Milton Santos em suas obras "Metamorfose do espaço habitado" "O Brasil: território e sociedade no inicio do século XXI"; Marcelo Lopes de Souza em artigo "O território: sobre espaço e poder. Autonomia e desenvolvimento" publicado no livro 
"Geografia Conceitos e Temas", além de Claude Raffestin com a obra "Por uma geografia do poder". O objetivo desse texto consistiu em elencar a discussão sobre o conceito de região, porém compreende a importância em se estudar o território para maiores discussões devido a grande interrelação entre ambos os conceitos na geografia, por conta da relação desenvolvida pela Globalização.

Sabe-se que ao longo da história a região tomou novas formas, consequentemente, novas funções foram delineadas no intuito de (re) organizar o espaço geográfico, esse que com o processo de globalização se transforma a cada momento num curto espaço de tempo intermediado pelo meio técnico-científicoinformacional.

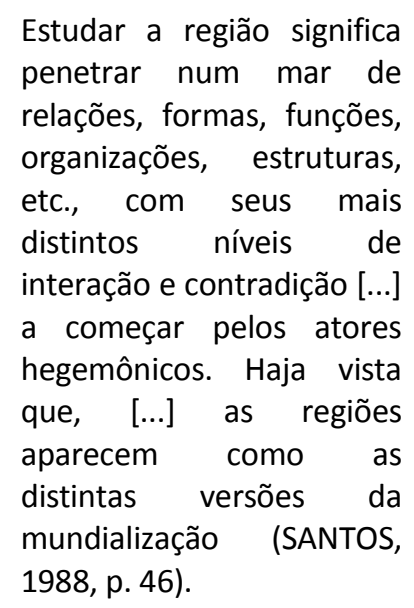

Nesse processo, a região passa a ser entendida por meio das relações mundiais existentes entre o fluxo de mercadorias e de bens materiais e imateriais, elementos esses que ditam o ritmo de desenvolvimento de uma determinada região. Para Lencioni (1999), a região é entendida na perspectiva economicista por meio do desenvolvimento desigual, cujos espaços de atuação dos fluxos e fixos referem-se ao campo de circulação. Nesse processo é importante compreender a região como um todo, levando em consideração os aspectos sociais, econômicos e ambientais, pois nesse caso a região torna-se a dimensão particular no processo de valorização do capital.

Dessa forma, o estudo regional vem desempenhando um importante papel, principalmente no quesito de interpretar e compreender a realidade por meio das diferentes maneiras que o modo de produção vem se especializando/reproduzindo em áreas distintas do Planeta, não respeitando as fronteiras.

\section{CONSIDERAÇÕES FINAIS}

No texto acima trabalhado procuramos exercer um diálogo com vários autores que contribuíram para o entendimento da evolução do pensamento geográfico e com o conceito de região como categoria de análise. Nesse processo, os estudos nos possibilitaram analisar de forma mais crítica o conceito de região, isto é, de forma mais integrante ao processo de organização e reorganização territorial.

Entretanto, compreende-se que os conceitos, as metodologias e as teorias utilizadas pelos respectivos autores, sejam eles no processo de construção do pensamento geográfico ou na elaboração do conceito de região, se divergem e convergem em alguns momentos, em busca do melhor entendimento do objeto de estudo, dado a complexidade em se estudar a região como um todo. Nesse sentido, procurou-se estabelecer a maior interrelação entre os autores $e$ as respectivas teorias e os conceitos em busca da melhor compreensão e entendimento do objeto de estudo.

Contudo, sabe-se que a própria Geografia, no decorrer de sua confirmação como ciência geográfica se transformou-retransformoutransfoma, e que ainda hoje sofre constantes reformulações perpassando por esse processo. Nessa perspectiva, o conceito de região não foge a regra, pois seu processo não poderia ser diferente, em detrimento de o conceito encontrar-se inserido numa das áreas científicas da Geografia que procura discuti-lo.

Alguns autores, ao trabalhar com o conceito de região, apresentam uma grande divergência, pois um grupo de estudiosos refere ao termo como elementos naturais, por outro lado, temos outros estudiosos que afirmam que é algo já materializado, principalmente após a configuração territorial. Temos outra corrente, que afirma que ela é o objeto do Estado para a promoção de políticas públicas em detrimento do desenvolvimento local. Nesse sentido, é importante compreender que a percepção deles está atrelada a fragmentação do território, visto de certa forma em retalhos, dividido, cuja finalidade é a intervenção do Estado em detrimento do desenvolvimento.

\section{REFERÊNCIAS}

CAMPOS, R. R. A Escola alemã de geografia. Geografia, Rio Claro, v. 26, n. 2, ago. 2001, p. 967. 
CORRÊA, R. L. Região: um conceito complexo. In: . Região e organização espacial. 8. ed. São

Paulo: Ática, 2007. p. 22-50.

GOMES, P. C. da C. O Conceito de Região e sua Discussão. In: CASTRO, I. E. ; GOMES, P. C. C.; CORREA, R. L. (Orgs). Geografia: conceitos e temas. 12. ed. Rio de Janeiro: Bertrand Brasil, 2009. p. $40-76$.

LENCIONI, S. Região e geografia. 1. ed. São Paulo: Universidade de São Paulo, 1999. p. 36-189.

MOREIRA, R. O que é geografia. 14 ed. São Paulo: Brasiliense, 1994. p. 17-46. (Coleção Primeiros Passos)

SANTOS, M. Categorias tradicionais, categorias atuais. In: Metamorfoses do espaço habitado. São Paulo: HUCITEC, 1988. p. 45-60.

Recebido para publicação em: 10/04/2017

Revisado em: 12/06/2017

Aceito em: 29/06/2017 